\title{
Study on Green Enterprise Quality Management Based on Sustainable Development
}

\author{
Lihui Sui ${ }^{1, ~ *}$, Hong Shao ${ }^{2}$, Yudong Wang ${ }^{3}$ \\ ${ }^{1}$ Department of Business, Shanghai Dianji University, Shanghai, China \\ ${ }^{2}$ Department of Financial Management, Shanghai Dianji University, Shanghai, China \\ ${ }^{3}$ School of Economics, Harbin University of Science and Technology, Harbin, China
}

Email address:

suilh@sdju.edu.cn (Lihui Sui), suilihui@163.com (Lihui Sui), Shaoh@sdju.edu.cn (Hong Shao),

Wangyudong2003@126.com (Yudong Wang)

${ }^{*}$ Corresponding author

\section{To cite this article:}

Lihui Sui, Hong Shao, Yudong Wang. Study on Green Enterprise Quality Management Based on Sustainable Development. International Journal of Natural Resource Ecology and Management. Vol. 4, No. 5, 2019, pp. 129-135. doi: 10.11648/j.ijnrem.20190405.14

Received: August 5, 2019; Accepted: August 23, 2019; Published: September 5, 2019

\begin{abstract}
Total quality management (TQM) is one of the quality-oriented approaches that many organizations imply and has been considered the important basis of competitive advantage of the organizations. Since the concept of sustainable development was put forward, global green awareness has continued to rise, and the world economy has moved toward a greener direction. Under the global green demands, the traditional ideas of TQM can not adapt to the development of enterprises to provide the green products. Meeting the green demands, the enterprises should pay attention on environmental production, focus on green products demands, ideas of TQM should be shifted from total quality management to the innovation of Green Enterprise Quality Management under the sustainable development environment. Based on the requirements of the sustainable development strategy, to meet the growing demand of the green consumption and to improve the sustainable competitiveness of the enterprise, the ideas of green enterprise quality management was proposed and its characteristics were analyzed. Comparison with total quality management, the similarities and differences between TQM and the Green Enterprise Quality Management were further further. The conclusion of this paper is that the implementation principles of Green Quality Management should be adhered to when the enterprises provide green products under sustainable development.
\end{abstract}

Keywords: Sustainable Development, Green Quality Management, Total Quality Management

\section{Introduction}

Since the 1990s, consumers' demand for green products increased constantly. According to statistics, $65 \%$ of Americans, $59 \%$ of Germans, 31 percent of the Japanese consider its impact on the environment as a very important factor when choosing the merchandise [1]. In daily life, more and more people pay more attention to "green" than ever, they concerned about green and healthy living environment for residential. They prefer green environmental protection materials when decorating house. Sustainable green conception gradually penetrate into the activities of the various national economies aspects. Integrated quality, environmental, occupational health and safety management systems (IMS) are well known and deployed by various industries with different level of success [2].

World Commission on Environment and Development (WCED), 1987 published in "Our Common Future", propose the concept of sustainable development, the general meeting "World Environment and Development," held in Rio de Janeiro, Brazil, 1992, formally proposed the strategy of sustainable development, and drew up the "Agenda 21". The documents take the sustainable development as a central task, deepened man's understanding of resources, environment and development, it combine the resources, the environment and socio-economic development and other issues together and establish a mutual coordination concept between resource environment and development [3-4]. Both the nation's government and the enterprises of the world have worked 
harder than ever to promote the sustainable development between resource environment and development. The "China's Agenda 21" was approved at the State Council executive meeting of the tenth, in March 25, 1994. On the basis of the country's specific national conditions and the overall requirements of development, the documents proposed the overall strategy and policy program of measures of promoting economic, social, resources, environment and population, education inter-coordination and sustainable development [5]. In 21st century, high-quality guided development and environmental forcing are two routes for China's green development [6]. The environment (waste material/water; air pollution; water supply; noise; green procurement) was considered much more by Japanese manufacturing multinational enterprises to be related to corporate sustainability when deciding on the location or significant expansion of their subsidiaries [7].

Since almost all the world's commercial activities revolve around products and services, products and quality of services are of great value for consumers and taking great responsibility for the survival of organization. Sustainability is emerging as an important approach that manufacturing companies employ to improve their economic profitability and competitive advantage by enhancing environmental performance [8]. Product quality requirements, quality design, quality manufacturing, sales, service and disposal after the end of the life cycle, a series of process of resource use, selection, disposal technology and management issues are all linked to sustainable development directly. Examining the quality of products in Sustainable Development terms is of great sign ificants [9].

The ideas and methods of quality management play an important role in improving the competitiveness of enterprises [10-12]. With the increasing and deepening awareness of sustainable development, the traditional mode of competition of ignoring the impact on the environment has changed. The growing environmental pollution has led various stakeholder groups to demand that enterprises protect the natural environment. Therefore, more enterprises are bringing green products to the market and are implementing eco-friendly activities based on green business [13]. Following the four major competitive factors, quality, cost, effectiveness and service, environmental protection has become the fifth competitive factor closely related with the competitiveness of enterprises. The activities of 'environmental management and green production' include all efforts to minimise the adverse environmental impacts of a firm's processes and products throughout their life-cycle [14]. As an advanced management concepts, total quality management has almost become one of the dominant type of enterprise managements (Total Quality Management, referred to TQM). With the increasing green consciousness, Environmentally healthy and promote healthy green concepts must be integrate into total quality management in order to achieve sustainable competitiveness and process improvement [15-18].

\section{Based on Sustainable Development of Green Enterprise Quality Management}

\subsection{Meaning of Green}

In accordance with public opinions and rules, the meaning of green is thought to be responsible for the environment, which includes the following particulars: Products are saved and recycled and are fully utilized the natural resources, products are non-toxic and do not contain other radioactive substances, conserved energy and water, minimized environmental impact during the process of manufacturing [19].

It has been said that "green" is an image expression here, refers to all the programs, actions, thoughts, ideas, activities of protecting earth's ecological environment, It gives the organization a certain degree of social responsibility. As to achieve economic benefits, but also to achieve certain ecological benefits, social benefits [20-21].

Greening the supply chain is increasingly a concern for many business enterprises and a challenge for logistics management in the 21 st century. Of particular concern is how to arouse organizational environmental awareness and put environmental activities into practice in the logistics activities of their supply chains. It includes not only the harmony between man and nature, but also the harmony between people, harmony and all things and make things lively. Green symbolizes life [22-23].

Green represents life, on behalf of health and vitality, is the color of hope. Green is understood as life, energy-saving and environmental protection three aspects internationally. The essential characteristics of the green directly reflected in the $5 \mathrm{R}$, namely, resource conservation, pollution reduction (reduce); green living, green optional (reevaluate); repeated use, multiple use (reuse); classified recycling, recycling (recycle); protection naturally, things coexist (rescue) and so on [24].

Green contains harmony, energy saving, environmental protection three aspects. Green symbolizes harmony, the harmony between the people, man and society, man and the environment, business and enterprise, business and society, business and environmental [25]. Green represents energy saving, environmental quality management emphasizes the active conservation of resources and energy. Green represents environmentally protection, green quality management means quality management activities is responsible for the environment, harmonious and environmental thinking and behavior means an effort which an enterprise makes directed toward a sustainable development goal, therefore, the green symbolizes the sustainable development.

\subsection{Meaning of Green Quality Management}

The green quality in this paper is actually bring in the ideas of conservation harmonious and environmentally 
friendly "green" on the traditional total quality basis, on the basis of meeting consumers' green demand, considering the needs of social, resource and environment, bringing the consumer satisfaction and social development, environmental protection, energy conservation and other aspects of satisfaction into harmony.

The definition of green quality management in this paper: Enterprise green quality management is that the enterprise integrate the conservational harmonious and environmentally friendly "green" concept into the total quality management, taking the green quality as the quality of the strategic objectives. Pay more attention to life, management of resources and environment, full participation, bear the quality responsibility of the entire life-cycle of product, process or service on the traditional basis of total quality management. While pursuing the balance of large-scale systems beyond the traditional scope of economic organization, society, resources and environment, meet consumers' green demand and obtain sustainable development themselves at the same time.

\subsection{The Features of Green Quality Management}

(1) Beyond the traditional total quality, the pursuit of broad green quality. In addition to meet customers' needs in a satisfactory product performance and quality, the traditional total quality also includes delivery time, efficiency, life cycle, maintainability and quality costs, etc. Lack of resources and the environmental considerations, the scope of quality is relatively narrow to industrial ecosystems. Generalized quality should be the enterprise green quality, which brings the conservational, harmonious, environmentally friendly green concepts on the basis of the meaning of total quality management.

(2) Quality-oriented extension. With economic development, quality management theory and methodology have developed dynamically. Early quality requirement is the product quality requirement which is also the suitability of the product. In addition to the further development of quality products, but also to ensure the quality of work and quality of service, advance to meet consumer demand, market demand. The quality requirements under green quality control will continue to extend. In a larger range of the industrial ecosystem which includes environmental markets, the quality should be met the expanding market requirements including products, services, consumers, markets and expanding markets.

(3) Expansion of the scope of quality management. The scope of the quality management have developed from taking product as a core traditionally, to the process of the formation, and the process of network development today, namely the whole organization of enterprise, but in the face of sustainable development, its scope is still limited. It ignores the production process of the impact on the environment, ignoring the efficient use of resources, as well as the impact on the environment after the product enter the consume field to the final end of life. Green Quality Management Quality Management under the scope of the organization will be more scope, that product - process - organization beyond the business organization.

(4) The unity of green ideas and methods of quality management strategy. Traditional corporate environmental quality management adopt cleaner production technologies. Carry out the ISO 14000 certification product life cycle assessment and green design, green manufacturing methods etc. Most belong to ways and means, and did not rise to the corporate strategic level, lack of appropriate quality culture, lack the appropriate quality culture. The enterprise should first established the green quality strategic when implementing green quality management. Guiding ideology first, and follows the technical methods. Establish the green quality management system, model. Combine a variety of green technologies, methods more effectively, and unify the ideas and methods.

(5) The Unify of Internal Quality and External Quality. The traditional overall quality management pay more attention to the quality of inner and outer quality of enterprise organization. The process of consumption and consumer products upon termination of disposal may still pollute the environment, the degree of impact on the environment depends on the quality of the design and formation. Therefore, the green quality management requirements assume lifelong responsibility, enterprises will internalize external quality, the harmonization of both inside and outside, and contribute to the overall ecological environment green.

\section{The Relationship Between Green Quality Management and Total Quality Management}

On the basis of traditional total quality management, green quality management pays attention to conservation and environmental protection under the guidance of the sustainable development strategy, the management thinking take development of enterprises and the ecological environment as origin. It is based on the idea of total quality management which is also the further improvement of total quality management. Total quality management and quality control of the dominant ideology green are very different, but because the activities are all undertaken around product, process or system, there exists a lot in common.

\subsection{The Green Quality Management and Total Quality Management in Common}

(1) Take the customers as the focus Whether the total quality management or green quality management, quality management activities are the final output of products or services, so customer demand for the 
product or service is the primary consideration for enterprise organizations. In the environment of total quality management, companies should understand, recognize, and identify customers' needs and expectations, in particular, to understand and identify the characteristics of the product requirements, establish the policy consistent with the customers' needs and objectives maintaining communication with customers, measuring customer satisfaction. Green quality management should also consider the customers' need characteristics firstly, on the basis of which, research and analysis the selection of resources and energy. Further considerate green art and technology, carrying on a production process planning for appropriate environmental protection, produce healthy products.

(2) Leading Role Business leaders must establish the unit purpose and direction of the organization, create an internal environment for employees and enables them to participate actively in and to make efforts to achieve the organization's goals. Whether it is green quality management or total quality management, the leadership plays a key role in creating the management thinking and the implementing the management activities. They not only have to develop appropriate quality policy and quality objectives, but also to create and provide a good and stable working environment to motivate employees to work creatively and fully participate in quality management in order to achieve the quality policy and objectives. Such as creating a culture of quality, caring staff, value its brainpower, providing staff with the necessary training opportunities and so on, and being able to lead by example to set an example for employees.

(3) The Role of the Team The employees at all levels are the root of the enterprise organization, only by their joint participation and talents can generate revenue for the enterprise. Longitudinal needs of enterprise quality work are from highest leadership of the correct principles and policies guiding down to junior officers' active implementation, needing their common coordination to accomplish, horizontal needs collaboration of various functional departments involving consistency operation and joint efforts of staff from various departments to generate positive synergies in order to improve organizational performance. Quality work is not just the quality department's work, but also the production department, purchasing department, training department, supply department, sales department, service department, etc. The development of the quality activities needs to determine the various departments and levels of quality objectives, to clear all kinds of quality staff duties, to promote the implementation of QC group activities actively. Strengthen training, assessment in order to improve the overall quality of staff, further improving the organization's performance.

(4) Continuous Improvement The eternal goal of business organizations is continuously improving the established quality management system, continuously improving the basic idea that meeting the quality management--PDCA cycle, PDCD represent Plan (Plan), Do (execute), Check (check), Action treatment), the increased cycling up four-stage. Like all things, the quality management is evolving, having a process of adapting the constantly update, quality improvement is endless. Companies should establish the appropriate information systems and feedback systems, the opportunities for understood, identify and improvement, master the improved technologies and methods, guidance and tracking quality improvement, promote and carried out the continuous improvement activities extensively and intensively.

\subsection{The Difference Between the Green Quality Management and Total Quality Management}

The current total quality management failed to achieve true "comprehensive " due to environmental aspects, The concept of total quality management does not take the environmental factors into account, while the strict sense of the definition of quality is not only to satisfy customers' needs in the traditional sense of satisfaction persistently, but also be able to maintain harmonious and friendly, the value of a higher level of satisfaction, which also shouldn't harm the natural environment in the production process and the handling of the final product, the difference between green quality management and total quality management can be explained from the following aspects, Table 1 .

Table 1. The Comparison between Green Quality Management and Total Quality Management.

\begin{tabular}{|c|c|c|}
\hline Contrast Factors & Total Quality Management & Green Quality Management \\
\hline the Goals & The satisfaction of customers and organization & $\begin{array}{l}\text { The overall satisfaction of organizations, social, } \\
\text { environmental systems }\end{array}$ \\
\hline Management objectives & $\begin{array}{l}\text { Achieve zero defects, continuous improvement and efforts } \\
\text { to reduce the final product inspection }\end{array}$ & $\begin{array}{l}\text { Make efforts to reduce the environmental impact during } \\
\text { process of the production, and to achieve zero-impact }\end{array}$ \\
\hline Management scope & Enterprises organization & Organizational, social, environmental large-scale systems \\
\hline Responsibility for quality & $\begin{array}{l}\text { Internal and products, processes, systems related } \\
\text { responsibilities }\end{array}$ & $\begin{array}{l}\text { Internal and external unity, the product of lifelong } \\
\text { responsibilities }\end{array}$ \\
\hline Environmental protection & $\begin{array}{l}\text { The concept of total quality management in not involved, } \\
\text { but the means, methods involved in, such as cleaner } \\
\text { production, ISO } 14000 \text { certification, product life cycle } \\
\text { assessment, etc }\end{array}$ & $\begin{array}{l}\text { Green quality management itself pays attention to } \\
\text { environmentally conscious strategic thinking, combined } \\
\text { with clean production, ISO } 14000 \text { certification, product life } \\
\text { cycle assessment methods etc. }\end{array}$ \\
\hline
\end{tabular}




\begin{tabular}{lll}
\hline Contrast Factors & Total Quality Management & Green Quality Management \\
\hline \multirow{2}{*}{ Strategic decision-making } & $\begin{array}{l}\text { maximize the benefits of enterprise organization maintain a } \\
\text { win-win for the supply-requisitioning parties. }\end{array}$ & $\begin{array}{l}\text { Focus on long-term development, organization maintain a } \\
\text { win-win-win for the supply-requisitioning parties and the } \\
\text { environment. }\end{array}$ \\
Driving force & Customer demand-driven & Customer green demand-driven \\
\hline
\end{tabular}

\section{The Implementation Principles of Green Quality Management}

(1) Beyond the Satisfaction of Customer's Demand for Green, and to Pursuit the Satisfaction of All Relevant Parties Enterprises should pay attention to, identify, meet customers and other stakeholders needs and expectations of green, including the current, potential and future needs, to ensure that all relevant parties are able to benefit. This refers to not only a variety of customers, but also refers to business owners, employees within the enterprise, the enterprise outside suppliers, partners, relevant organizations, social and ecological environment.

(2) People-oriented, Full Participation in The Green Quality Management Business executives advocate that taking the green quality as the enterprise quality objectives, to inspire the stuff's spirit of cooperation and ownership, mobilize the enthusiasm of the employees, bring attention to the development of enterprises and make efforts to make the employees satisfied. At the same time, strengthen the education and training of green quality culture for all the staff, while paying attention to the self-improvement of staff, encouraging their learning exchanges, improving staff s' quality.

(3) The Whole Process of Green Quality Management The whole process Includes from market research and product development, to the product design, manufacture, delivery, after-sales service, the consumption process to dispose of end of life. It can be divided into internal processes and external procedures, As to the development, formation, implementation, marketing and maintenance of all the quality factors and resource conservation and environmental protection, prevention-oriented control, using the process methods of green quality management. Internalize the external process quality, make the possible quality problem eliminate before or being formed.

(4) Responsibility for All Quality Life The pursuit of green quality management is based on the overall satisfaction of business, society, resources and environment coordinated development of large-scale systems. Focus on the quality of the product life cycle, the disposal entered for consumption until the end of life of which the external quality's impact on the environment has a direct relationship with the corporate design, production, packaging and other processes. External quality should be internalized and the enterprise should take the responsibility for life.

(5) Scientific Decision-Making and the Green Technology Quality Methods In order to successfully achieve the green quality management, we must use scientific, practical quality decisions to determine the quality policy and objectives, positioned for quality correctly. Under the green quality strategy, the enterprise set the goal and objection for the development of quality, at the same time, use process approach to establish the green quality management system, identified and managed the process used and the relationship between them systematically, identify the ordinal relationship between the process, determine the input and output in each process, to make sure the activities, resources desired and support process can achieve the transformation of inputs into outputs, then make sure the control criteria and methods, and then improve them by using the operation and monitoring, keep using an effective method of green quality management to analyze, to promote energy conservation, environmental protection and further solve quality problems.

(6) Continuous Improvement, the Pursuit of Excellence To achieve sustainable development of enterprises and access to long-term success, we need the continuous improvement, improving opportunities, analyzing from resources, technology, methods, and other aspects of the environment, we should not only seek to improve on the original basis, but also requires constant innovation, pursuit the excellence in performance.

(7) Win-Win-Win with the Supplier and Environment Under the traditional total management environment, emphasis on organization and supply-side interdependent, mutually beneficial relationship can enhance the ability of both to create value. With increasingly serious ecological crisis, human interests and the interests of other species as well as the Earth has been intertwined with each other solidarity, asking people not to chase the interests of humanity desperately, to consider the relationship between supply and demand sides only in a win-win way, it must be considered as a whole between human and nature or from the entire ecosystem to consider the interests of harmony between man and nature. It requires people to recognize that all things, including humans are interrelated in essence. The choice of humanity interests are bound by the limits of the overall dynamic structure of nature. Establish the relationship of interest between the suppliers and environment, to achieve win-win-win situation keeping within the limits of the value of natural systems. 


\section{Conclusion}

As the sustainable development of green quality management is an inevitable trend in the development of quality management, it can adapt to the social sustainable development requirements and meet consumer demand for green community, it is also a further improvement the total quality management. Under the guidance of green quality strategy of environmental protection, saving idea, the enterprises make their efforts to achieve zero pollution, to achieve a real sense of defect ultimately, to achieve sustainable development goals.

\section{References}

[1] Chialin Chen. Design for the Environment: A Quality-Based Model for Green Product Development. Management Science 2001, Vol. 47, No. 2: 250-263.

[2] Mežinska; Iveta; Lapiṇa; Inga, Mazais; Jānis. Integrated management systems towards sustainable and socially responsible organisation. Total Quality Management \& Business Excellence 2015, Vol. 26 Issue 5/6, p 469-481. 13p.

[3] Liqun Du. Resources, environment and sustainable development. Bejing Univercity Press 2003. 117-123.

[4] Qinghua Zhu; Joseph Sarkis. The Link between Quality Management and Environmental Management in Firms of Differing Size: An Analysis of Organizations in China. Environmental Quality Management 2004, Spring: 53-64.

[5] Li Jingjiang. Green production: Qinghua Press 2006, 2-40.

[6] Zhengda Li; Wanping Yang; Chengjun Wang; Yuesheng Zhang; Xiaoling Yuan. Guided High-Quality Development, Resources, and Environmental Forcing in China's Green Development. Sustainability 2019, vol. 11, issue 7, 1-18.

[7] Masayoshi Ike; Jerome Denis Donovan; Cheree Topple; Eryadi Kordi Masli. A holistic perspective on corporate sustainability from management viewpoint: Evidence from Japanese manufacturing multinationalenterprises. Journal of Cleaner Production 2019, Volume 216, 10 April, Pages 139151.

[8] Koo; Chulmo Chung; Namho; Ryoo; Sung Yul. How does ecological responsibility affect manufacturing firms' environmental and economic performance?. Total Quality Management \& Business Excellence 2014, Vol. 25 Issue 9/10, p 1171-1189.

[9] Amalia Venera Todorut. Sustainable development of organizations through total quality management. Procedia Social and Behavioral Sciences 2012, 927-931.

[10] Frank Wiengarten; Mark Pagell. The importance of quality management for the success of environmental management initiatives. International Journal of Production Economics 2012, 407-415.

[11] Christian N. Madu. Achieving Competitive Advantag Through Quality and Environmenttal Management. Environment Quality Management 2004, Winter: 59-76.
[12] Brian P. Mathews; Akiko Ueno; Tauno Kekale; Mikko Repka; Zulema Lopez Pereira \& Graca Silva. Quality Ttrainng: Needs and Evaluation-Findings From a European Survey. Total Quality Management 2001, 483-490.

[13] Chen Jui-Ho; Wu Shwu-Ing. A comparison of green business relationship models between industry types. Total Quality Management \& Business Excellence 2015, Vol. 26 Issue 7/8, p 778-792. $15 \mathrm{p}$

[14] Yang Ching-Chow; Yang King-Jang; Peng Shu-Yun. Exploration strategies and key activities for the system of environmental management. Total Quality Management \& Business Excellence 2011, Vol. 22 Issue 11, p 1179-1194.

[15] Chin, K. S E.; Pun, K. F. \& Hua, H. M. Consolidation of China's Quality Transformation Efforts: a Review. International Journal of Quality \& Reliability Management 2001, 836-853.

[16] Brian P. Mathews; Akiko Ueno; Tauno Kekale; Mikko Repka; Zulema Lopez Pereira and Graca Silva. Quality Ttrainng: Needs and Evaluation-Findings From a European Survey. Total Quality Management 2001, 483-490.

[17] Richard Reed; David J Lemak; Neal P Mero. Total quality management and sustainable competitive advantage. Journal of Quality Management 2000, 5-26.

[18] Noor Azlina Mohd. Salleh; Salmiah Kasolang, Ahmed Jaffar. Green Lean Total Quality Information Management in Malaysian Automotive Companies. Procedia Engineering 2012, 1708-1713.

[19] Bruce Clemens; Thomas J. Douglas. Does Coercion Drive Firms to Adopt Swings 'Voluntary' Green Initiatives? Relationships Among Coercion, Superion Firm Resources, and Voluntary Green Initiatives. Journal of Business Research 2006, 483-491.

[20] J. P. Ulhøi; H. Madsen; S.. Hildebrandt. Green new world: A corporate environmental business perspective. Scandinavian Journal of Management 1996, 243-254.

[21] Bruce Clemens; Thomas J. Douglas. Does Coercion Drive Firms to Adopt Swings 'Voluntary' Green Initiatives? Relationships Among Coercion, Superion Firm Resources, and Voluntary Green Initiatives. Journal of Business Research 2006, 483-491

[22] Qinghua Zhu; Joseph Sarkis; James J. Cordeiro; Kee-Hung Lai. Firm-level correlates of emergent green supply chain management practices in the Chinese context. Omega 2008, $577-591$.

[23] Hwang; Yeong-Dong Wen; Yuan-Feng Chen; Mu-Chen. A study on the relationship between the PDSA cycle of green purchasing and the performance of the SCOR model. Total Quality Management \& Business Excellence 2010, Vol. 21 Issue 12, p 1261-1278.

[24] Zhaohui Wu, Mark Pagell. Balancing priorities: Decisionmaking in sustainable supply chain management. Journal of Operations Management 2011, 577-590.

[25] Lihui Sui. Research on the construction and process management of enterprise green quality management system. Doctoral thesis of Harbin Institute of Technology 2007, 28-34. 


\section{Biography}

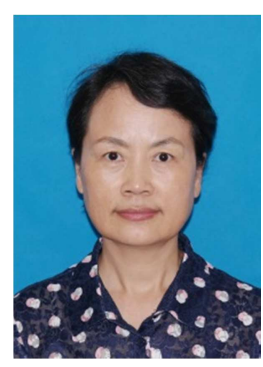

Lihui Sui, PhD of Management Science and Engineering of Harbin Institute of Technology, Professor of Business School of Shanghai Dianji University, Shanghai, China. Teaching in Shanghai Dianji University on some courses of quality management and quality cost managemnt. The current research focus on quality management including quality management theory and methods. This project is supported by Academic Discipline Project of Shanghai Dianji University. 